\title{
BMJ Open Determinants of physician networks: an ethnographic study examining the processes that inform patterns of collaboration and referral decision- making among physicians
}

\author{
Patrick Kierkegaard (D) ,,2 Jason Owen-Smith ${ }^{3,4}$
}

To cite: Kierkegaard $\mathrm{P}$, Owen-Smith J. Determinants of physician networks: an ethnographic study examining the processes that inform patterns of collaboration and referral decision-making among physicians. BMJ Open 2021;11:e042334. doi:10.1136/ bmjopen-2020-042334

- Prepublication history for this paper is available online. To view these files, please visit the journal online (http://dx.doi. org/10.1136/bmjopen-2020042334).

Received 02 July 2020 Revised 04 December 2020 Accepted 10 December 2020

Check for updates

(C) Author(s) (or their employer(s)) 2021. Re-use permitted under CC BY-NC. No commercial re-use. See rights and permissions. Published by BMJ.

${ }^{1}$ NIHR London In Vitro Diagnostics Co-operative, Department of Surgery and Cancer, Imperial College London, London, UK

${ }^{2}$ CRUK Convergence Science Centre, Institute of Cancer

Research \& Imperial College

London, London, UK

${ }^{3}$ Institute for Social Research, University of Michigan, Ann Arbor, Michigan, USA

${ }^{4}$ Department of Sociology, University of Michigan, Ann Arbor, Michigan, USA

Correspondence to Dr Patrick Kierkegaard; p.kierkegaard@imperial.ac.uk

\section{ABSTRACT}

Objective Most scholarly attention to studying collaborative ties in physician networks has been devoted to quantitatively analysing large, complex datasets. While valuable, such studies can reduce the dynamic and contextual complexities of physician collaborations to numerical values. Qualitative research strategies can contribute to our understanding by addressing the gaps left by more quantitative approaches. This study seeks to contribute to the literature that applies network science approaches to the context of healthcare delivery. We use qualitative, observational and interview, methods to pursue an in-depth, micro-level approach to the deeply social and discursive processes that influence patterns of collaboration and referral decision-making in physician networks.

Design Qualitative methodologies that paired ethnographic field observations, semistructured interviews and document analysis were used. An inductive thematic analysis approach was used to analyse, identify and describe patterns in those data.

Setting This study took place in a high-volume cardiovascular department at a major academic medical centre (AMC) located in the Midwest region of the USA. Participants Purposive and snowballing sampling were used to recruit study participants for both the observational and face-to-face in-depth interview portions of the study. In total, 25 clinicians and 43 patients participated in this study.

Results Two primary thematic categories were identified: (1) circumstances for external engagement; and (2) clinical conditions for engagement. Thematic subcategories included community engagement, scientific engagement, reputational value, experiential information, professional identity, self-awareness of competence, multidisciplinary programmes and situational factors.

Conclusion This study adds new contextual knowledge about the mechanisms that characterise referral decisionmaking processes and how these impact the meaning of physician relationships, organisation of healthcare delivery and the knowledge and beliefs that physicians have about their colleagues. This study highlights the nuances that influence how new collaborative networks are formed and maintained by detailing how relationships among physicians develop and evolve over time.
Strengths and limitations of this study

- Qualitative descriptive research stays close to the perspective of clinicians and patients. The study observed and interviewed a broad variety of participants in a busy clinical environment.

- The study sheds light on the contextual nuances of how collaborative ties in physician networks emerge, gain meaning and evolve using qualitative methods.

- The research design triangulates across three sources of evidence (observations, interviews and documents) to provide rich data for qualitative analysis, ensure the face validity of results and represent multiple participant perspectives.

- The study took place at a major academic medical centre in the Midwest. As such, the participants observed and the experiences related by our interviewees may not reflect the perceptions and experiences of all clinicians and patients in cardiovascular medicine.

\section{INTRODUCTION}

Health systems are burdened with a high volume of medically complex cases that tend to accompany populations requiring significant specialty care. ${ }^{1-3}$ At the same time, they face challenges posed by resource limitations, upward trends in specialty care referral rates, projected shortages of specialists and growing healthcare expenditures. ${ }^{4-8}$ Developing synergies through collaboration among physicians with diverse areas of expertise has been identified as a key component of structural reforms and of strategies to address these concerns while improving health outcomes. ${ }^{910}$ Against this background, interest has risen in applying the techniques from social network analysis (SNA) to the context of healthcare delivery to examine associations between the quality of care and the myriad of professional relationships that 
connect physicians in the course of their care-giving work (referred herein as physician networks) ${ }^{11-14}$ The bulk of scholarly attention in SNA has been devoted to analysing large complex datasets to reveal clusters of collaborating physicians who share patients, information and clinical decisions, ${ }^{15-20}$ and to measuring the frequency and intensity of shared activities. ${ }^{21-23}$

However, the quantitative nature of these studies also reduces the dynamic and contextual complexities underlying relationships to numerical values. ${ }^{24-26}$ As such, understanding the contextual nuances of how collaborative ties in physician networks emerge, gain meaning and evolve has not been widely researched. ${ }^{27-29}$ Qualitative, inductive research strategies are well suited to help address these gaps because they can help 'open up and explore complexities boxed off in quantitative work', ${ }^{30}$ and investigate the context and understanding of the social processes that shape referral decision-making behaviours. ${ }^{31-33}$ Thus qualitative research can be a very effective means to evaluate concepts that are difficult to measure quantitatively. In doing so, this research helps add depth and nuance to our understanding of referral networks. We focus attention on patterns of referral decision-making because such decisions represent a key social mechanism underpinning the formation and evolution of physician collaboration around shared patients and cases. We also unravel new aspects of how physicians experience and make sense of their work environments, consciously and subconsciously evaluate cases and colleagues and make care decisions. ${ }^{34-36}$

This paper seeks to contribute to the literature by using qualitative methods to add an in-depth understanding and micro-level perspective on the deeply social and discursive nature of the collaboration and referral decision-making in physician networks. The findings of this study can help inform policies, practices and procedures to strengthen collaborative ties and the organisation of physicians and groups within and across clinical care settings to support quality and safety improvement.

\section{MATERIALS AND METHODS \\ Setting and context}

This study conducts naturalistic research through the application of qualitative methodologies for data collection and analysis in order to generate a 'thick description' of detailed people, processes and settings underpinning physician networks. ${ }^{37}$ This allowed us to examine microlevel experiences, patterns of behaviour, attitudes, decisions and actions of individuals and groups, as well as to directly observe formal and informal interactions in the clinical setting. ${ }^{38}$

To reach an appropriate degree of internal validity, triangulation across three sources of evidence provided rich data for qualitative-inductive analysis, to ensure validity and examination of multiple perspectives on collaboration and decision-making. ${ }^{39}$ Ethnographic field observations, interviews and document analysis supported a detailed analysis of the data to render rich in-depth understandings of concepts and identify thematic descriptions. ${ }^{41} 42$

This study took place in a high-volume cardiovascular department that treated medically complex patients at a major academic medical centre (AMC) located in the Midwest region of the USA. We selected an AMC cardiovascular department as our primary study site for two reasons. First, AMCs have 'long provided the criterion standard for subspecialised care of medically complex patients' ${ }^{43}$ Second, cardiovascular diseases are a leading health problem that often requires specialist care and accounts for a significant amount of healthcare spending. ${ }^{44}$

\section{Sample and participant recruitment}

To obtain detailed, rich, real-life data, we used purposive sampling and snowball sampling methods to recruit participants for both the observational and interview portions of the study. ${ }^{45}$ The initial set of respondents were senior faculty members in the medical centre's cardiac surgery department. A description of the study was presented at one of the weekly department faculty meetings. This was followed up by purposefully and carefully contacting specialists and members of their care team by e-mail with a description of the study and estimated time commitment. Subsequent clinician respondents were recruited using snowball sampling, where respondents were asked to identify other respondents who could provide additional insight, who in turn name other respondents, making sure that different points-of-view would be considered. ${ }^{39}$ Using this snowball sampling, we continued to identify, recruit and interview subsequent clinician study participants until we reached the point of saturation, that is, we determined that was when no new information was learnt by the study team through new interviews and observations with snowball sampled participants. ${ }^{46}$

To ensure representative credibility, specialists and members of their team who were recruited for this study represented different clinical backgrounds and experiences. This included cardiac surgeons, interventional cardiologists, heart failure cardiologists, advanced practice providers and clinical care coordinators. These differences in clinical experience helped generate a collection of thoughtful, often unique responses that represented different viewpoints within each profession and across different but complementary specialisations. Recruitment was not restricted in terms of age, gender, place of work or organisational role. In addition, we recruited patients invited to participate in interviews at the end of observed clinical encounters with participating caregivers. Patient interviews provide additional insight into the processes that led to their referral to particular specialists at the AMC.

All study participants provided their written and informed consent to be observed and interviewed. Each participant received a copy of the consent form. All participants who agreed to participate in the study were assured 
of confidentiality, for this reason, all names that appear in the Results section of this article have been anonymised and assigned a unique ID to protect their identity. All interview participants were compensated US\$50 MasterCard for their time.

\section{Data collection}

Three trained investigators (one male postdoctoral fellow, one male doctoral student and one female doctoral student) with extensive experience in qualitative research conducted all the field observations, document retrievals and participant interviews. Field observations and interviews with clinicians took place between March 2018 and January 2019. Interviews with patients took place between September 2018 and December 2018.

During field observations, investigators observed clinical workflow and medical encounters for over 230 hours. The investigators paid particular attention to the interactions among clinicians and to medical encounters between clinicians and patients. All patients read a plain language statement and provided their written and informed consent prior to having their medical encounter observed by the study team members and all patient data were deidentified on collection. The typical length of patient-clinician encounters ranged from 15 to 20 min between patients and advanced practice providers and 10 to $15 \mathrm{~min}$ between patients and cardiac surgeons, reflecting the average 30 -min time slot allocated for consultations. As time permitted, investigators also conducted informal, conversational, interviews during the course of observations to better understand aspects of clinic behaviours that were difficult to comprehend based solely on watching interactions. Following each site visit, investigators transcribed all field notes after observation along with written reflections, stored them securely in an electronic document and immediately anonymised all participants during the fieldwork periods. The initial notes helped refine observations and formulate topics to consider during additional observations in the clinics.

In total, 25 interviews were conducted with eight surgeons, three interventional cardiologists, four heart failure cardiologist, five clinical care coordinators and five advanced practice providers. Of the interviews 24 were face-to-face at the participants' workplace and 1 was conducted by telephone. In addition, 43 patients (25 males and 18 females) were interviewed after their consultation with a cardiac surgeon. Thirty-nine of the patients resided in-state, whereas four of the patients travelled from out-of-state. Patients represented a range of conditions (including coronary artery disease, heart valve disease and thoracic aortic aneurysm) and were under consideration for treatment options that included coronary artery bypass grafting, aortic aneurysm repair, heart valve repair, heart valve replacement and heart transplant. Table 1 details participant demographics. All study participants interviewed provided their written and informed consent form prior to being interviewed. Some family members of patients were present during the interview
Table 1 Summary of interviewed participant demographics

Number

\begin{tabular}{lc}
\hline Clinician characteristics & \\
Professional role & 8 \\
$\quad$ Surgeon & 4 \\
\hline Heart failure cardiologist & 3 \\
\hline Interventional cardiologist & 5 \\
\hline Clinical care coordinator & 5 \\
\hline Advanced practice provider & \\
\hline Gender & 14 \\
\hline Male & 11 \\
\hline Female & \\
\hline Patient characteristics & \\
\hline Gender & 25 \\
\hline Male & 18 \\
\hline Female & 39 \\
\hline Geographical area & 4 \\
\hline In-state & \\
\hline Out-of-state & \\
\hline
\end{tabular}

and were asked to sign the study consent forms. Interviews were conducted following a semistructured interview guide that was developed and refined through training and mock interviews to elicit detailed and thoughtful answers. During the interviews, study participants had the flexibility to dwell on questions and were encouraged to speak openly regarding their personal experiences regarding referrals pathways and social networks.

During the interviews with clinicians, name generator questions were used to collect information on study participant networks, ${ }^{47}$ that is, each interviewee was asked to name colleagues within and outside the AMC with whom he/she has engaged in previous collaborations with such as shared patient care, joint research efforts and knowledge-exchange activities. Interviewees were also asked to characterise the strength of the relationships they reported. Each question was followed up with appropriate probing and elaboration queries to help guide and redirect the conversation when necessary. At the end of the interview, participants were asked to share any information that they felt was relevant that we had not asked. This method was successful in engaging the participants and in prompting their discussion of factors that they might not have otherwise spontaneously volunteered. Interviews lasted between 30 and $45 \mathrm{~min}$, which was consistent with the time period of which participants were informed. No participants dropped out of the study during the data collection process.

All interviews were audio recorded, professionally transcribed verbatim (including all the interviewer's interjections) and anonymised. To ensure accuracy, audio recordings were compared against the transcript by study team members. Data collection was supplemented by 
document analysis, ${ }^{40}$ which included both public and internal department reports, brochures, internal memoranda's, staff guidelines and e-mail exchanges. The information from these sources was used to complement and validate the field observations and interview data.

\section{Patient and public involvement}

Patients and the public were not involved in the design, planning or reporting of the study.

\section{Data analysis}

An inductive thematic analytic approach was applied to interview, field observation and documentary data. We adopted this approach because it allowed us to document the social processes underpinning patterns of interaction and referral decision-making in a bottom-up fashion that was sensitive to the specific context of physician networks and our field site. ${ }^{48}$

All transcribed data were coded using the software program IBM NVivo V.11 (QSR International). Transcripts and field notes were read and reread by multiple study team members to ensure understanding of the parts within the context of the whole. ${ }^{49}$ An axial coding strategy was used to collate and group codes that occurred repeatedly together, or shared conceptual similarities into thematic categories and subcategories. Throughout the analysis, a constant comparative method was used, in which data were continuously compared and contrasted both within and between transcripts. ${ }^{50}$ The analysis process was carried out until no new themes judged by the researchers emerged from the data. ${ }^{51}$ The themes we describe in this study emerged from this iterative approach to coding and analysis. The most revealing quotes were selected to illustrate the results of our analysis. Quotes from participants are provided to illustrate the themes, and participants have been allocated an anonymised ID to protect their identity.

\section{RESULTS}

The empirical data analysis identified, two primary thematic categories: (1) circumstances for external engagement; and (2) clinical conditions for engagement (see table 2). Following an ethnographic tradition, both these themes and their subthemes are listed, not according to statistical occurrence, but based on a synthesis of information from the various data sources. Readers are encouraged to view the results holistically, as a picture representing a whole phenomenon-that is, a global view of the factors that influence the occurrence of referrals decision-making and patterns within physician networks. In the following sections, we describe each of these themes in further detail and offer evidence from our analyses, including quotations from participants, to support these findings.

\section{Theme 1: circumstances for external engagement}

Circumstances for external engagement encompass activities that facilitate the formation and strengthening of relationships between specialists and primary care providers (PCPs).

Table 2 Themes that inform the decisions concerning choices and patterns of interactions between physicians

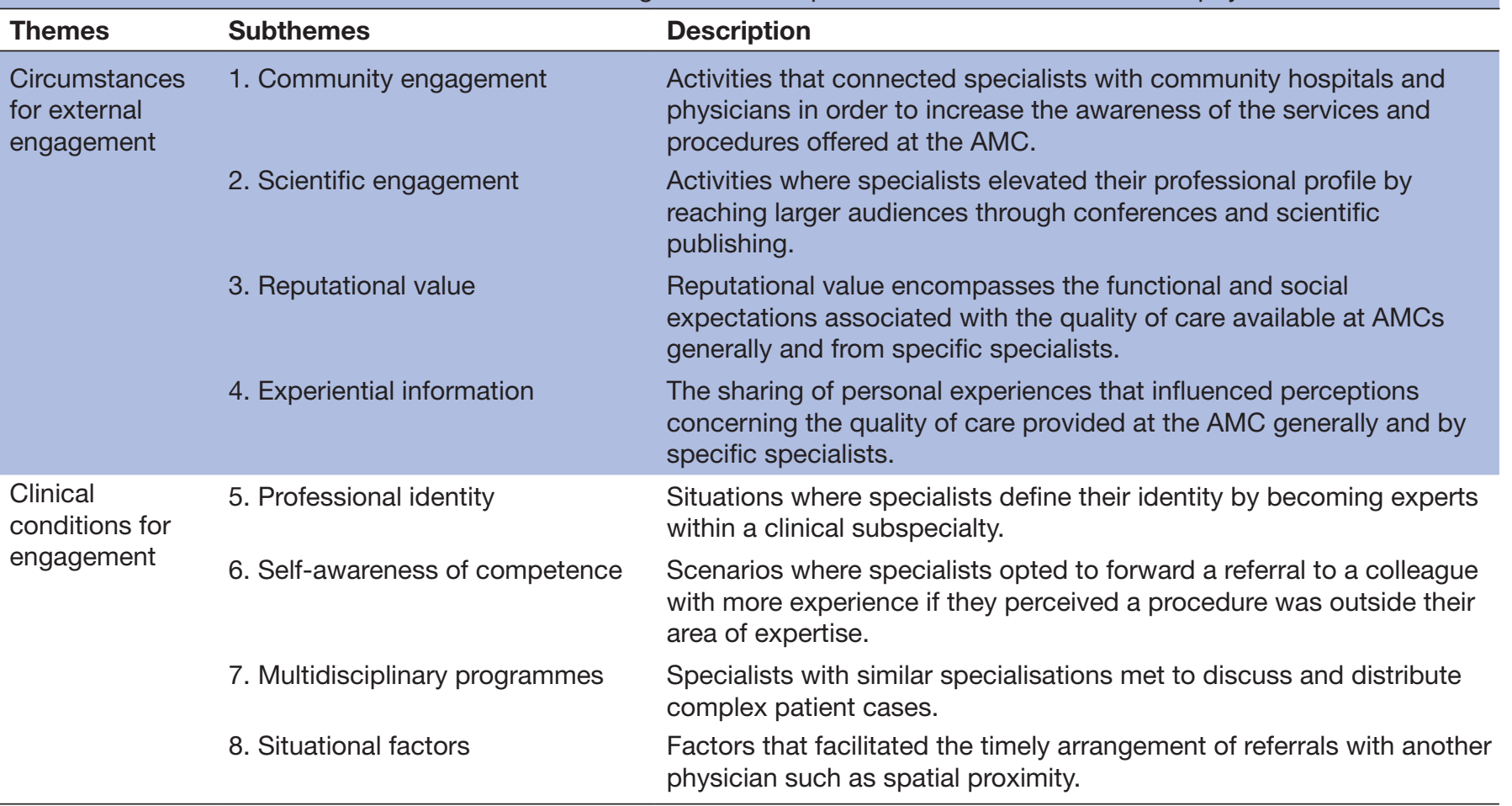

AMC, academic medical centre. 


\section{Community engagement}

This subtheme highlights activities that connected specialists with community hospitals and other external physicians in order to increase the awareness of the services and procedures offered at the AMC. Although these activities presented the clinical benefits of referring patients to the AMC, specialists emphasised the importance of using these opportunities to establish and develop personal relationships with PCPs. As one surgeon explained,

You can't sit here and be an ivory tower. You have to go out into the community. You have to let them know what you can do. You need to go out and collaborate and partner with them. You have to let them know who you are... we broke down those barriers by going out there and eating with them. Shaking hands with them. Talking with them. Joking with them. Learning about their families. Telling them about our families. They realize we're human beings. That we wanted to work with them. We always respected them and treated them with dignity. You have to go out there and you have to mingle with them. You have to build a relationship. The best way to do it is personally. (Cardiac surgeon 01)

However, concerns were also expressed that current efforts still leave room for improvement.

Our faculty need to go out and meet people more. I think places like Cleveland have been very good about that. They require their faculty to go out and present, they identify practices. They would have different people for the different practices so that you have a face that goes with the communication. There are people who automatically send you cases (Interventional cardiologist 03)

Subsequently, developing familiarity with the community providers had the reciprocal effect of influencing specialists in their decision-making process when initiating an outgoing referral to PCPs that matched the patient's needs.

I know all these cardiologists. I've known them for a long time. I do think about the patient, and I think about who they may connect with. You think about certain characteristics of the patients and who I think may be best suited for them, not only in terms of their knowledge base, but we're all humans, and some humans interact better with other people, and think about who would be the best interaction for the patient. (Cardiac surgeon 08)

The image here is one where relationships outside the focal AMC and participant specialties are considered essential to individual practitioners' ability to receive and to make appropriate external referrals. These quotes also suggest the importance of personal relationships and of the kinds of reputational factors we describe below.

\section{Scientific engagement}

This involves activities where specialists elevated their professional profile by reaching larger audiences through conferences and scientific publishing. This aided them in developing referral networks that extended beyond regional and state boundaries. One surgeon explained,

90 percent or 80 percent (of my incoming referrals) is from a cardiologist who's seen me in a meeting, or heard of me, or something like that. (Cardiac surgeon 04)

Related to this, one patient explained that their referring PCP chose to refer her to a specialist based on having attended a lecture given by that specialist at a conference.

We're fortunate that he [referring provider] was at a conference and saw [name of surgeon] speak at the conference about pulmonary hypertension. (Patient 34)

Here the emphasis is less on developing personal relationships than on the value of active research as a means to increase clinical visibility and with it, referrals.

\section{Reputational value}

Reputational value encompasses the functional and social expectations associated with the quality of care available at AMCs and specific specialists. For example, when asked to explain why he chose to get a referral to the AMC, one patient said:

When I knew I needed to have a procedure done, nobody has a better reputation than [name of AMC]. I have a bicuspid aortic valve, which is a congenital heart defect. I actually read online that recently [name of AMC] was an accredited center for congenital heart defects. I decided it'd be good to seek out a doctor who was an expert in adult congenital heart defects, and so I contacted that department. (Patient 22)

Similarly, community PCPs often referred complex patients because of the positive reputational value associated with high-volume AMCs being better equipped and capable of providing care for extreme and challenging cases. For example, one cardiologist said,

We don't get the bread and butter heart failure patient. Usually, we get very complex patients. Most of the time those patients have seen two or more cardiologists. Then, they're at the end of the road for being referred to us. (Heart failure cardiologist 01)

One patient explained that his referring provider sent him to the specialist at the AMC based on the knowledge that a specific type of procedure was available at the AMC, which they were unable to provide,

I discussed that with my doctor but the actual move to come here was by my doctors treating the atrial fib and the water retention problem. When they had 
heard that-about the possibility of a catheterization for replacing the tricuspid valve here at [name of AMC], which they didn't have-they did it with the open-heart surgery. That was the primary reason for coming here. (Patient 41)

\section{Experiential information}

The sharing of experiential information also impacted reputational value as it influenced perceptions concerning the quality of care provided at the AMC and by specific specialists. For example,

I think I've built it [my reputation] based on patients I've operated on, who've gone back to their cardiologist or PCP and have said nice things about me. Then, there are a few in the community, who do tend to send me patients based on the ones I have already operated on. If I've built up a referral, I think it's based on reputation of what I've done. (Cardiac surgeon 05)

I talked to my friends, local friends. There is a worker here, she is a respiratory therapist, she's a family friend to us for about 25 years. She's a respiratory therapist here. And I talked to her and she says, why don't you come to [AMC location]? [Name of surgeon] is the best. And, then I said I'd research on her, and went online and studied about her. Then I said, okay, let's do it. (Patient 15)

The four subthemes we identify as components of the larger theme illuminate key processes that support the formation and deepening of clinical collaboration networks. Outreach and development of personal relationships with external physicians, the visibility that highprofile research activities can bring to a physician's clinical practice, the established reputation of the specialist and of the AMC as a whole, and 'word of mouth' means to gain experiential knowledge about a given specialist or medical centre all play important roles in directing patients to the hospital, the practice and individual clinicians.

\section{Clinical conditions for engagement}

Clinical conditions for engagement consist of factors that inform the decisions to directly refer a patient to a specific specialist or group of specialists.

\section{Professional Identity}

Specialists explained the importance of developing a 'niche' or specific area of expertise within a clinical subspecialty to define their professional identity. One surgeon explained,

Each of these clinicians, they've done extra training or as part of their practice they've sought out these types of cases develop an expertise. At an academic institution, in order to really thrive, you need to have a level of expertise higher than the community, so to speak. That's what we all strive to do is reach a level, a unique area of other practice that we become an expert in. (Cardiac surgeon 02)

Subsequently, developing the reputation as an expert within a clinical subspecialty led to specialists becoming preferentially selected as the primary recipient for specific types of incoming referrals that fell within their domain of expertise. For instance, one cardiac surgeon explained,

I think there are certain types of operations that there's only a small group of us that specialize in, like heart failure. All the referrals from internal referrals for heart failure will always come to [name of surgeons]. These are patients who need a VAD, or patients who are being evaluated for heart transplant. Any cardiologist within the system or cardiologists out in the community, they will refer to just [name of surgeons]. (Cardiac surgeon 08)

During our observations, one surgeon explained that he receives referrals as a result of his extensive experience and reputation in performing a very particular type of surgery,

You know how many mitral valve repairs other surgeons in this country do in a year? For the average surgeon, it's about five. Okay? Five surgeries of this kind in a year; maybe a hundred of them or so in the average surgeon's career. You know how many I do? I do six thousand. Six thousand of these cases a year. So, you know, write that down - THAT'S why people refer to me. It turns out that, generally speaking, the more you do something, the better you are at it. (Observation, 1 October 2018)

This study also found that senior specialists attracted more directed referrals as they had established higher levels of experience and professional visibility in a subspecialty in comparison to junior faculty members. One advanced practice provider explained,

Part of that I think is because although older surgeons find their own niche and only do one type of surgery and the younger are more jack-of-all-trades. Say for instance, [name of surgeon] does a lot of mitral valve.... So, [name of surgeon] had a referral basis of people sending just mitral-valve repairs for a long time and so, they send it directly to [name of surgeon] because they know his/her name. With [surgeon name], it's the same way. Because he's been an aortic surgeon who does aortic valve disease almost all of his direct referrals even though he hasn't been operating for more than twoyears, he still gets direct referrals based on those issues. (Advanced practice provider 09)

These quotes bring to attention the significant role that strategic career development and good repute has in setting the stage for the new relationships and preferences in collaborations within networks. 


\section{Self-awareness of competence}

This theme encompasses scenarios where specialists opted to forward a referral to a colleague with more experience if they perceived a procedure was outside their area of expertise. One surgeon explained,

If the patient is sent to me, and I feel like it's not in my comfort zone, then I will send it to one of my partners. For example, we had a patient who had a congenital aortic anomaly and would benefit from an operation that I don't have as much experience with, then I referred it to a specific surgeon that I thought had more experience. I think that's the responsibility of all of us, that we should only be offering the operations that were comfortable doing. (Cardiac surgeon 08)

In another example, we observed a situation where a patient who had previously received aortic surgery was internally referred to another surgeon who had more experience in aortic surgery.

Her cardiac care started with an aortic dissection, replaced at St. Joe's in June. Then she had a dilating aortic root that prompted a valve-saving root procedure. She developed bleeding from that procedure, which led her doctors at St. Joe's to refer her to [cardiac surgeon 07]. As of today she was dealing with valve leakage and left ventricular dilating... [name of surgeon] greeted her and started by noting, You saw [cardiac surgeon 07]. My specialty is aortic surgery and I take many Marfans patients. The issue is you have a leaky aortic valve. The leaky valve doesn't need surgery, but your heart function is going down-that's why you need surgery. You need a prosthetic aortic valve. (Observation, 18 October 2018)

Other issues raised included the perceived experience and positive outcomes of their colleagues in particular conditions. As explained by a patient and heart failure cardiologist,

He was recommended because I'm a kidney transplant patient, and he had already done the bypass surgery on a kidney transplant patient before... [the referring provider] said he [the surgeon] did this same procedure on a kidney transplant, and that it went really well, and because of his surgeries before that she totally recommended him hundred percent. (Patient 17)

In addition to a deep and visible area of expertise, the quotes we highlight in this subtheme indicate the importance of a clear understanding of what a physician does and does not know. Here, perceived levels of experience and expertise among colleagues influence how relationships form and evolve in relation to the distribution and reassignment of referrals.
Multidisciplinary programmes

Specialists collaborated through 'multidisciplinary programmes' where complex cases were often presented and discussed, which often led to referrals and case assignments. Such programmes strengthened internal referral patterns and facilitated patient sharing among the specialists. As the following physicians explained:

We discuss the cases. Then we'll bring up cases that may be candidates for transplant or candidates for VAD. We share patients, as well. We're covering the medical complications for the VAD patients as well. (Heart failure cardiologist 05)

I do particularly send [referrals] to those four [cardiologists] because I work with them through TAVR (Transcatheter aortic valve replacement). (Cardiac surgeon 05)

This activity was also observed during the field observations:

The patient was recently discussed at the CATH conference meeting where surgeons present a patient case that requires more discussion and consensus from surgeons concerning treatment. [name of physician] presented the patient at the meeting and then referred him to [name of surgeon]. (Observation, 2 May 2018)

Within this context, the formation of interdisciplinary treatment programmes supports the establishment of synergetic clinical collaboration networks. The stronger familiarity with colleagues' specialisations influences how patterns of internal referrals develop among specialists who interact in interdisciplinary collaborations.

\section{Situational factors}

This theme involved the factors that facilitated the timely arrangement of referrals with another physician. Here, spatial proximity between physician offices encouraged real-time engagement between physicians. In the following observation, one specialist visited a colleague clinic to initiate an internal referral,

Within a minute [interventional cardiologist 07] enters the staff room. He tells Dr. Luke that he is referring a patient to him for a mitral valve surgery and begins discussing the septum approach... [They] take a look together at some imaging for the patient that they are discussing. [cardiac surgeon 02] says, 'It's a tough case.... There's not much muscle....' and then adds 'cavity obliteration'. [interventional cardiologist 07] says that he has 'loaded him up (meds) and I can't do anything else...' (Observation, 21 March 2018)

When asked to elaborate on the occurrence of these type of scenarios, one cardiologist explained,

I think having us in the same building has been really helpful. Having their clinics being up there. 
We're up there. That's the best. You can go down the hall and see people. Run cases by them.... If I know they're in clinic-if it's Tuesday, then I know (name of cardiac surgeon) in clinic I'll walk down there and just have a chat with him. Then I'll put in the referral on MyChart. (Heart failure cardiologist 05)

Additionally, having a means to directly contact another physician through various communication modalities enabled easier and timely access to arrange referrals. One heart failure cardiologist said,

We generally will say, 'Yes,' to somebody who, if a colleague is calling you to see a patient and it really sounds like they need to be seen, you see them on some day that you don't normally see patients, which, you know, you don't really want to do because it cuts into your time to do the other stuff you're supposed to doing. Obviously, it somebody's calling you need your help, you're going to do that.... That's where sort of the informal network, I guess, come into the play (Heart failure cardiologist 02)

The subthemes discussed herein provide insight into the conditions that facilitate and inform the processes related to distributing directed referrals to specific physician specialists. Here, establishing a niche expertise in clinical subspecialties, internally redirecting referrals to colleagues with stronger expertise in particular procedures, engaging in interdisciplinary collaborations, and the ability to quickly access a colleague, all play a critical role in the processes of how referrals are preferentially assigned or distributed to specific specialists.

\section{DISCUSSION}

This study applied qualitative techniques to examine the social processes that influence patterns of collaboration and referral decision-making in physician networks. Two primary themes were identified. They were each characterised by a diverse range of subthemes. Together these themes represent multiple levels of social processes that together help influence how connections are formed and built in physician networks. The situated social processes that help to drive tie formation have potential effects on the larger networks that are often the target of more quantitative research.

We found that 'circumstances for external engagement' led to the initiation and emergence of personal relationships with community PCPs that could become the basis for later professional collaborations. Notably, outreach activities in the form of community and scientific engagement raised awareness of specialists' professional profile, affecting their reputations and offering another means for these activities to influence patterns of collaboration and referral. Community engagement provided specialists with opportunities to develop personal relationships and simultaneously negate any preconceptions of arrogance or pretentiousness associated with working at an AMC. ${ }^{52}$

Here, positive impressions and interactions led to equally important associative memories for community PCPs. This indicates the importance of leaving positive first impressions, as the quality of specialists' interactions with community physicians can have profound effects in determining the future of their relationship. ${ }^{53}{ }^{54}$ Moreover, it emphasises that developing and maintaining positive relationships depend on prosocial behaviour qualities with humility being a critical variable that facilitates social bonding across different professional disciplines and specialties ${ }^{55}$ Considering this, interpersonal communication, humility and social bonding described by the study participants should be recognised as an important strategic tool in network building, developing a referral base and forming strategic alliances. ${ }^{56}$ On the other hand, scientific engagement was less personal but still increased the profile of a specialist among the wider academic and medical community. This study found cases where referrals were based on scenarios where specialists provided lectures or spoke at conferences that subsequently led to new referrals. This suggests that an active research agenda and engaging with the community on a 'macro' level positively influences specialists' professional profiles, creates new social connections and influence community PCPs referral decision-making.

Moreover, it indicates that conferences and lectures function as venues for dynamic network formation because they provide the social conditions for the transmission of scientific knowledge that bridges the gaps between research evidence to the local/regional perspective. In doing so, these events foster the formation of social ties between specialists and community physicians by creating meaningful opportunities for them to develop complementary and reciprocal patient-sharing relationships. ${ }^{57} 58$ Broadly speaking, these factors illuminate the importance of professional networking in scientific engagement as it assists specialists build a broader sphere of influence, establish contacts for collaboration and develop a reputation at the institutional, local and national levels. ${ }^{575960}$

In addition, the 'reputational value' associated with the institutional stature and resources available at an AMC led to a steady influx of incoming referrals for patients with rare and complicated conditions or requiring complex procedures and advanced expertise. Societal perceptions of the resources and subspecialties available at an AMC may play a role in a selective decision-making process, ${ }^{43}$ suggesting that networks are shaped by the contexts in which they grow in multiple ways. For instance, perceptions that AMCs deliver higher-quality care and better outcomes in comparison to non-teaching hospitals can also act as a mechanism that motivates referring physicians and patients' referral preferences. ${ }^{61-65}$ In particular, patients and referring physicians' preferences for healthcare facilities can be influenced by the AMCs and specialist 
departments' performance in national rankings and the public release of performance data. ${ }^{66-68}$ Here, prominent ranking systems such as the US News \& World Report (USN\&WR) places significant emphasis on reputation. ${ }^{67}$ Consequently, rating systems effect public perception of a hospital's quality, ${ }^{69} 70$ and patients can equate their perception of hospital reputation with perceived quality of care. ${ }^{71}$

Hospitals can experience a 5\% change in patient volume from year-to-year as a result of rank changes in the USN\&WR. ${ }^{72}$ However, relying on rankings where reputation bears significant weight may convey a false sense of precision as it does not necessarily differentiate patient clinical outcomes among hospitals as well as the quality of healthcare services across all subspecialties. ${ }^{73}$ Nevertheless, the reputation and overall public recognition of an institute suggest that societal perception is an antecedent factor that motivates referrals to be sent to specific hospitals and subspecialty departments. ${ }^{74} 75$

'Experiential information' also had implications on referral decision-making strategies. Previous studies suggest that PCPs and patients are influenced by the type of experiential information shared with them by patients and other physicians. ${ }^{76} 77$ Patient expectations and their actual experience with healthcare services are important influencing factors in their evaluation of care services. ${ }^{78} 79$ Interestingly, related studies have found that patients consider experience-based information a more valuable indicator of medical care quality in comparison to performance measurements, and that PCPs prefer informal sources of information when evaluating facilities and other physicians. ${ }^{80-84}$

This implies the important latent role of word-ofmouth in the referral decision-making process as one patient's shared experience can affect another patient's referral trajectory to a specific specialist. Moreover, it lends weight to existing findings that word-of-mouth plays a significant role in initiating specific referral requests where patients rely on the views of their family and friends and the advice of their PCP when choosing a hospital or specialist to be referred to. ${ }^{85-87}$ In this regard, social influence plays a central role in the way these types of information are shared with patients. ${ }^{88}$ As such, the level of trust that exists in the relationship between the patient and the individuals sharing the information can influence which facility or specialists a referral will be directed to. For example, patients who lean onto their PCP's recommendations may be associated with the higher levels of interpersonal trust that exists in the patient-physician relationship. ${ }^{89-94}$ Likewise, patients will typically consult with family and friends whom they consider as trustworthy and reliable sources for health-related information, are familiar with their condition, and have their best interest in mind ${ }^{95}{ }^{96}$ Altogether, these factors demonstrate that the interdependent relationship between experiential information and social influence are driving forces that influence referral decision-making processes for patients and physicians.
This study also found that 'clinical conditions for engagement' motivated referrals in terms of assigning referrals to specific specialists or groups of specialists based on subspecialties. This implies that pursuing a subspecialty as part of a specialist's 'professional identify' lays the groundwork for a referral pathway. Here, specialists emphasised developing a professional identity as part of the expectation of working at an AMC, which resonates with the anticipation of high-performing specialists contributing substantially to the prestige of their institutions by making advances in translational research and clinical programmes. ${ }^{97}$ Moreover, occupying a niche can be motivated by career development plans, where academic promotion requires that faculty members demonstrate that they have developed an outstanding local and regional reputation in an area of expertise..$^{99}$ This has implications on the social capital of specialists and how referral networks evolve as they strategically position themselves as experts in their respective subspecialities..$^{100} 101$

Some studies in academic medicine have suggested that 'graceful self-promotion' is an effective method that can increase public awareness around one's own expertise and accomplishments. ${ }^{102}$ In contrast, other studies state that developing a professional identify based on a subspecialty typically occurs over the course of a specialist's career and requires specialists to establish a track record of high-procedure volume and associated positive outcomes. ${ }^{103-105}$ This may explain why senior specialists receive a stronger stream of directed referrals in comparison to junior faculty members who were still working on establishing their niche. All things considered, these factors bring attention to the important interplay between social capital and establishing a professional identify as part of long-term plans to position themselves to preferentially receive an incoming flow of referrals unique to their specialty.

Although specialists desire to build and maintain a referral base, they were also aware of their own limitations. Thus, their 'self-awareness of competence' suggests that specialists set aside personal interests and the opportunity to directly strengthen their relational ties with community PCPs by forwarding the referral to another colleague. This suggests that networks are further shaped by different dimensions of humility. For instance, specialists who opt to forward a referral to colleagues with a stronger expertise in treating particularly complex conditions may be a result of 'intellectual humility', which pertains to one's insight concerning the limits of their knowledge and influence and openness to new ideas. ${ }^{106} 107$

Likewise, forwarding a referral to another expert colleague may be due to dispositional humility, which entails self-reflection and the ability to achieve a balance between the self-focused desire for recognition and meeting the needs of others. ${ }^{108-110}$ Consequently, forwarding patient referrals to a colleague also reveals that specialists informally take on the role as brokers in the network. That is, they become the intermediaries 
who facilitate new connections between their specialist colleagues and the referring PCPs in sharing the patients care. ${ }^{111} 112$ With this in mind, specialists informally occupy strategic positions in the network that provides them with greater influence on the prospective formation of new relationships between PCPs and their colleagues as they can broker the flow of referrals originally assigned to them. ${ }^{113}$ This can also lead to the negative effect of limiting opportunities for other specialists to care for the patient. ${ }^{114}$

For specialists, the role as a broker also carries with it the risk of diminishing the value of their importance in the network if their colleagues and PCPs develop long-term ties and the PCPs become less dependent on them. ${ }^{115} 116$ Additionally, the choice of colleague to reassign a referral to may be influenced by the perception or knowledge of who has been attributed the role of expert within the network. In other words, individuals who have been endowed with greater social capital by virtue of their position in the network. Overall, several of these processes provide insights into our understanding of the ways in which specialists informally and indirectly can shape the referral network of others. ${ }^{117}$

Specialists embedded in 'multidisciplinary programmes' developed preferences and tendencies to initiate internal and interdivisional referrals to other colleagues who also shared membership in the same programme to discuss diagnosis and assess the advantages and disadvantages of the various treatment strategies. ${ }^{118} 119$ Structural collaborations between departments such as these can foster community of and lead to a dense cluster of relationships among each other. ${ }^{120-122}$ Here, interdivisional referrals among specialists may be a result of the frequent and meaningful interaction as members within these clusters, which can foster confidence and trust, ${ }^{123}$ and lead to the bidirectional exchange of knowledge concerning each other's expertise. ${ }^{124}$ This echoes the findings from previous SNA studies, which found that physicians tend to share their patients within a small network of specialists with whom they are already familiar with, have a pre-existing relationship with, or share similar traits, reaffirming that multidisciplinary programmes strengthen collaboration and referral relationships. ${ }^{125-129}$

These preferences are linked to the homophily principle ${ }^{130}$ which states that similar individuals are more likely to interact with each other. However, it should be noted that local clustering within networks can both be positive and negative to their natural preference for ties with colleagues they are familiar with, ${ }^{122} 131$ as interdivisional referral decisions risk not extending beyond the boundaries of the cluster of specialists who are affiliated with the same specialty programme. Interestingly, specialists who are embedded in several groups can harness the benefits of 'structural folding' as a result of their clearer understanding of their colleagues expertise in the different groups that they are members of. ${ }^{132}$ Specifically, specialists can take on the role as brokers by recommending referrals be sent to a colleague from within the one group to their colleagues who are members of another group. ${ }^{133}$

Finally, 'situational factors' also affected interactions in the work environment and subsequent interdivisional referral. Within the building, spatial proximity between specialists' offices or clinic increased the likelihood for specialists to engage in face-to-face communication. As such, spatial proximity acted as a social mechanism that supported the exchange of complex information and subsequent real-time transfer of referrals between specialists. Considering this, the interplay between spatial layouts and physician networks suggests that proximity can strengthen internal referrals between specialists. Existing studies on spatial proximity have found that physical space can hinder or enhance the formation of social ties and networks. ${ }^{134-136}$

As an alternative to spatial proximity, different communication modalities, such as direct telephone calls by specialist colleagues and PCPs, were also used to quickly arrange referrals. Similar studies have found that telephone or e-mail can help support timely and informative communication and increase satisfaction between PCP and specialists. ${ }^{137138}$ This implies the important interplay between timeliness, culture and multimodal communicative methods used by physicians to arrange referrals between specialists within a timely manner. ${ }^{139}$ For PCP and specialist relationships, timely and ongoing communication could mitigate fears of leaving PCPs with losing the patient to the system and the perception of being out of the loop. ${ }^{140}$

In this paper, we demonstrate that ethnographic approaches to SNA offer valuable insights into the social processes underlying the structural properties of physician networks. In particular, it lends support to the discussions that qualitative data can increase the depth or breadth of the data and establish a stronger link between patterns at the structural level and contextual level. ${ }^{1524141} 142$ Our findings suggest that an ethnographic approach can effectively address the analytical constraints of quantitative techniques in the analysis of physician networks. This raises the prospect of studies in physician network adopting more mixed-methods approaches to make avail of the strengths of both qualitative and quantitative techniques in SNA..$^{30} 143144$ In particular, a mixed-methods approach can cultivate a deeper understanding of physician collaborations, the processes informing decisionmaking behaviours, as well as reveal what community structures exists at the collective level. ${ }^{145-147}$ In addition, both techniques can be used interdependently, where the results obtained by one method can inform the design of the other method. ${ }^{148-150}$ For instance, the ethnographic findings generated from our study could feed directly into the research design of a larger-scale networks study (and vice versa) or be used to indicate the validity of field observations in connection with structural patterns.

However, mixed-methods come with some challenges due to the resource implications of running such a study. ${ }^{150}{ }^{151}$ Furthermore, there is a risk that the whole 
study could be adversely impacted if either the qualitative and quantitative components have been poorly designed and executed. ${ }^{152}$ Also, network researchers may hesitate to utilise mixed-methods as quantitative approaches require extensive methodological explanations and qualitative guidelines for SNA remain vague. ${ }^{143}{ }^{149}$ Nevertheless, the dual analysis of qualitative-quantitative network analytics holds significant promise as it harness the full potential of SNA and generate a closer real-world representation of physician communities, which can inform clinical practice and health policy.

There are additional areas that can be targeted for future research based on the findings of this study. First, more work could explore the implications of formal referral alliances between healthcare organisations and collaborative care agreements. For example, new affiliations and alliances may bottleneck or disrupt existing referral decision-makings practices in the network if limitations are imposed on the physicians control over choice of specialist. ${ }^{153-155}$ Second, this paper introduced the concept of specialists also taking on brokerage roles when they opt to redirect a referral to their specialist colleague. This has wider implications for healthcare studies attempting to measure the structure of networks and 'actual' strengths of relationships within these networks, suggesting that the interplay between crossreferrals and brokerage roles in initiating new connections deserves more attention. Third, the increasing trend of larger, higher status hospitals sharing their brand identify with smaller affiliated hospitals can reshape network structures. Specifically, smaller affiliated hospitals may benefit from 'brand-sharing' with larger hospitals, which would result in an increase in incoming referrals based on patients and referring providers perceived higher quality of care based on the larger hospitals reputation. ${ }^{156-159}$ Thus, this area of research merits further investigation into the role of 'brand-sharing' on referral patterns, and its impact on reshaping of network structures as more hospitals continue to become affiliated with larger and highly ranked AMCs.

\section{LIMITATIONS}

The main limitation of this study is that the opinions of the clinicians and patients who participated in this study may not represent all physician networks in cardiovascular medicine. Furthermore, the study is limited to describing participants' experiences and answers are primarily applicable to a high-volume AMC known for its well-developed adult cardiovascular medicine programme. Nevertheless, our sampling approach involved interview data with a large sample of 68 participants to ensure that a diverse range of experiences and perspectives were included. This provided sufficient data to achieve saturation where such that no new themes were emerging from the data. ${ }^{160}$ Thus, we are confident that the credibility of the research and our sample are sufficiently diverse and that the findings presented here are an appropriate reflection of the dataset with the increased likelihood of transferability to other contexts.

\section{CONCLUSION}

This paper aimed to contribute to the growing body of research in the study of physician networks to better understand the social processes influence patterns of interaction and referral decision-making in physician networks. By applying qualitative methods, this study adds new contextual knowledge about the mechanisms that characterise referral decision-making and how these impact physician relationships, organisation of healthcare delivery and the knowledge and beliefs that physicians have of their colleagues. This study highlights the nuances that influence how new networks are formed and how relationship ties between physicians develop and evolve over time.

Acknowledgements The authors gratefully acknowledge and thank the physicians, advanced practice providers, clinical care coordinators and patients who allowed the research team to observe their daily workflow and took the time to share with us their thoughts and experiences throughout the interviews. The authors thank Mira D Vale and Spencer Garrison for their many hours of contributing to the data collection process. The authors thank Dr John M Hollingsworth for helping guide the design of the study. Funding for this study was obtained by Professor Jason Owen-Smith and Dr John M Hollingsworth.

Contributors PK drafted, edited and prepared the final version of the manuscript. PK collected the data and performed the qualitative analysis. JOS provided critical feedback, edited and approved the final version of the manuscript.

Funding This work was supported by the National Science Foundation (Award number 1560987).

Competing interests None declared.

Patient consent for publication Not required.

Ethics approval Ethics approval for this study was granted by the University of Michigan Medical School Institutional Review Board (Study ID: HUM00110788).

Provenance and peer review Not commissioned; externally peer reviewed.

Data availability statement No data are available. All data relevant to the study are included in the article.

Open access This is an open access article distributed in accordance with the Creative Commons Attribution Non Commercial (CC BY-NC 4.0) license, which permits others to distribute, remix, adapt, build upon this work non-commercially, and license their derivative works on different terms, provided the original work is properly cited, appropriate credit is given, any changes made indicated, and the use is non-commercial. See: http://creativecommons.org/licenses/by-nc/4.0/.

ORCID iD

Patrick Kierkegaard http://orcid.org/0000-0001-8600-7956

\section{REFERENCES}

1 Barnett K, Mercer SW, Norbury M, et al. Epidemiology of multimorbidity and implications for health care, research, and medical education: a cross-sectional study. Lancet 2012;380:37-43.

2 Ward BW, Schiller JS, Goodman RA. Multiple chronic conditions among US adults: a 2012 update. Prev Chronic Dis 2014;11:E62.

3 Goodman RA, Posner SF, Huang ES, et al. Defining and measuring chronic conditions: imperatives for research, policy, program, and practice. Prev Chronic Dis 2013;10:E66.

4 Liaropoulos L, Goranitis I. Health care financing and the sustainability of health systems. Int J Equity Health 2015;14:80.

5 Cohen S. The concentration and persistence in the level of health expenditures over time: estimates for the U.S. Population, 20122013. Statistical Brief \#481. Rockville, MD: Agency for Healthcare 
Research and Quality, 2015. http://www.meps.ahrq.gov/mepsweb/ data_files/publications/st481/stat481.pdf

6 Barnett ML, Song Z, Landon BE. Trends in physician referrals in the United States, 1999-2009. Arch Intern Med 2012;172:163-70.

7 Association of American Medical Colleges. The complexities of physician supply and demand: projections from 2017 to 2032, 2019.

8 An C, O'Malley AJ, Rockmore DN, et al. Analysis of the U.S. patient referral network. Stat Med 2018;37:847-66.

9 McDonald KM, Schultz E, Albin L. Care coordination atlas: version, 2014.

10 Cameron ID, Fairhall N, Langron C, et al. A multifactorial interdisciplinary intervention reduces frailty in older people: randomized trial. BMC Med 2013;11:65.

11 Greenwood-Lee J, Jewett L, Woodhouse L, et al. A categorisation of problems and solutions to improve patient referrals from primary to specialty care. BMC Health Serv Res 2018;18:986-86.

12 Landon BE, Keating NL, Onnela J-P, et al. Patient-sharing networks of physicians and health care utilization and spending among Medicare beneficiaries. JAMA Intern Med 2018;178:66-73.

13 Barnett ML, Landon BE, O'Malley AJ, et al. Mapping physician networks with self-reported and administrative data. Health Serv Res 2011;46:1592-609.

14 Pollack CE, Frick KD, Herbert RJ, et al. It's who you know: patientsharing, quality, and costs of cancer survivorship care. J Cancer Surviv 2014;8:156-66.

15 Berthod O, Grothe-Hammer M, Sydow J. Network ethnography: a mixed-method approach for the study of practices in interorganizational settings. Organizat Res Method 2017:20:299-323

16 Chambers D, Wilson P, Thompson C, et al. Social network analysis in healthcare settings: a systematic scoping review. PLoS One 2012;7:e41911.

17 DuGoff EH, Fernandes-Taylor S, Weissman GE, et al. A scoping review of patient-sharing network studies using administrative data. Trans/ Behav Med 2018;8:598-625.

18 Pollack CE, Soulos PR, Herrin J, et al. The impact of social contagion on physician adoption of advanced imaging tests in breast cancer. JNCl 2017;109:djw330.

19 Landon BE, Onnela J-P, Keating NL, et al. Using administrative data to identify naturally occurring networks of physicians. Med Care 2013;51:715-21.

20 Cunningham FC, Ranmuthugala G, Plumb J, et al. Health professional networks as a vector for improving healthcare quality and safety: a systematic review. BMJ Qual Saf 2012;21:239-49.

21 Uddin S, Hossain L, Hamra J, et al. A study of physician collaborations through social network and exponential random graph. BMC Health Serv Res 2013;13:234.

22 Hussain T, Chang $\mathrm{H}-\mathrm{Y}$, Veenstra CM, et al. Collaboration between surgeons and medical oncologists and outcomes for patients with stage III colon cancer. J Oncol Pract 2015;11:e388-97.

23 Pollack CE, Weissman G, Bekelman J, et al. Physician social networks and variation in prostate cancer treatment in three cities. Health Serv Res 2012;47:380-403.

24 Edwards G. Mixed-method approaches to social network analysis. Discussion paper NCRM, 2010.

25 Schipper D, Spekkink W. Balancing the quantitative and qualitative aspects of social network analysis to study complex social systems. Complex Governance Network 2015;2:5-22.

26 Bellotti E. Qualitative networks: mixed methods in sociological research. Routledge, 2014.

27 Symon G, Cassell C. Qualitative organizational research: core methods and current challenges. Sage, 2012.

28 Crossley N. The social world of the network. combining qualitative and quantitative elements in social network analysis. Sociologica 2010;4.

$29 \mathrm{Knox} \mathrm{H}$, Savage M, Harvey P. Social networks and the study of relations: networks as method, metaphor and form. Econ Soc 2006;35:113-40.

30 Edwards G, Crossley N. Measures and meanings: exploring the ego-net of Helen Kirkpatrick Watts, Militant suffragette. Methodol Innovat Online 2009;4:37-61.

31 Heath S, Fuller A, Johnston B. Chasing shadows: defining network boundaries in qualitative social network analysis. Qualitat Res 2009;9:645-61.

32 Crossley N, Bellotti E, Edwards G. Social network analysis for ego-nets: social network analysis for actor-centred networks. Sage, 2015.

33 Ahrens P. Qualitative network analysis: a useful tool for investigating policy networks in transnational settings? Method Innov 2018;11:205979911876981.
34 Waring J, Jones L. Maintaining the link between methodology and method in ethnographic health research. BMJ Qual Saf 2016;25:556-7.

35 Dixon-Woods M, Baker R, Charles $\mathrm{K}$, et al. Culture and behaviour in the English National health service: overview of lessons from a large multimethod study. BMJ Qual Saf 2014;23:106-15.

36 Jung T, Scott T, Davies HTO, et al. Instruments for exploring organizational culture: a review of the literature. Public Adm Rev 2009;69:1087-96.

37 Leslie M, Paradis E, Gropper MA, et al. Applying ethnography to the study of context in healthcare quality and safety. BMJ Qual Saf 2014:23:99-105.

38 Reeves S, Kuper A, Hodges BD. Qualitative research methodologies: ethnography. BMJ 2008;337:a1020.

39 Patton MQ. Qualitative research and evaluation methods. Thousand Oaks: Sage, 2002.

40 Creswell JW, Creswell JD. Research design: qualitative, quantitative, and mixed methods approaches. Sage, 2017.

41 Ethnography WTJ. reality, and truth: the vital need for studies of 'how things work'in organizations and management. Journal of Management studies 2011;48:202-17.

42 Hammersley M, Atkinson P. Ethnography: principles in practice. Routledge, 2007.

43 Youngerman BE, Bruce JN. Capturing quality: the challenge for high-volume academic medical centers. Mayo Clin Proc 2018;93:4-6.

44 Benjamin EJ, Muntner P, Alonso A, et al. Heart disease and stroke Statistics-2019 update: a report from the American heart association. Circulation 2019;139:e56-28.

45 Onwuegbuzie AJ, Collins KM. A typology of mixed methods sampling designs in social science research. Qualitative Report 2007;12:281-316.

46 Palinkas LA, Horwitz SM, Green CA, et al. Purposeful sampling for qualitative data collection and analysis in mixed method implementation research. Adm Policy Ment Health 2015;42:533-44.

47 Burt RS, Meltzer DO, Seid M, et al. What's in a name generator? Choosing the right name generators for social network surveys in healthcare quality and safety research. BMJ Qual Saf 2012;21:992-1000

48 Braun V, Clarke V. Using thematic analysis in psychology. Qual Res Psychol 2006;3:77-101.

49 Thorne S. Interpretive description: qualitative research for applied practice. Routledge, 2016.

50 Charmaz K. Constructing grounded theory: a practical guide through qualitative analysis. Sage, 2006

51 Rapley T. Some pragmatics of data analysis. In: Silverman D, ed. Qualitative research: theory, method and practice. , 2011: 3, 273-90.

52 Schein M. The rural surgeon and ivory towers. World J Surg 2006;30:1620-1.

53 Evans KR, Kleine RE, Landry TD, et al. How first impressions of a customer impact effectiveness in an initial sales encounter. J Acad Mark Sci 2000;28:512-26.

54 Harris MJ, Garris CP. You never get a second chance to make a first impression: behavioral consequences of first impressions, 2008.

55 Peters AS, Rowat WC, Johnson MK. Associations between dispositional humility and social relationship quality. Psychology 2011:02:155-61.

56 Davis DE, Worthington EL, Hook JN, et al. Humility and the development and repair of social bonds: two longitudinal studies. Self and ldentity 2013;12:58-77.

57 Kuwabara K, Hildebrand CA, Zou X. Lay theories of networking: How laypeople's beliefs about networks affect their attitudes toward and engagement in instrumental networking. Acad Manage Rev 2018;43:50-64

58 Casciaro T, Gino F, Kouchaki M. The contaminating effects of building instrumental ties: how networking can make us feel dirty. Admin Sci Quarterl 2014;59:705-35.

59 Goolsby MJ, Knestrick JM. Effective professional networking. J Am Assoc Nurse Pract 2017;29:441-5.

60 Covey SR, Covey S. The 7 habits of highly effective people. Simon \& Schuster, 2020

61 Shahian DM, Nordberg P, Meyer GS, et al. Contemporary performance of U.S. teaching and nonteaching hospitals. Acad Med 2012;87:701-8.

62 Burke LG, Frakt AB, Khullar D, et al. Association between teaching status and mortality in US hospitals. JAMA 2017;317:2105-13.

63 Mueller SK, Lipsitz S, Hicks LS. Impact of hospital teaching intensity on quality of care and patient outcomes. Med Care 2013;51:567-74.

64 Shahian DM, Liu X, Meyer GS, et al. Comparing teaching versus nonteaching hospitals: the association of patient characteristics 
with teaching intensity for three common medical conditions. Acad Med 2014:89:94-106.

65 Burke L, Khullar D, Orav EJ, et al. Do academic medical centers disproportionately benefit the sickest patients? Health Aff 2018:37:864-72.

66 Cua S, Moffatt-Bruce S, White S. Reputation and the best Hospital rankings: what does it really mean? Am J Med Qual 2017;32:632-7.

67 Sehgal AR. The role of reputation in U.S. News world report's rankings of the top 50 American hospitals. Ann Intern Med 2010;152:521-5.

68 Emmert M, Hessemer S, Meszmer N, et al. Do German hospital report cards have the potential to improve the quality of care? Health Policy 2014;118:386-95.

69 Huesch MD, Currid-Halkett E, Doctor JN. Public hospital quality report awareness: evidence from national and Californian Internet searches and social media mentions, 2012. BMJ Open 2014;4:e004417.

70 Yaraghi N, Wang W, Gao GG, et al. How online quality ratings influence patients' choice of medical providers: controlled experimental survey study. J Med Internet Res 2018;20:e99.

71 Ziemba JB, Arenberg S, Reustle H, et al. Consumers' association of hospital Reputation with healthcare quality. J Healthc Qual 2019;41:251-8

72 Pope DG. Reacting to rankings: evidence from "America's Best Hospitals". J Health Econ 2009;28:1154-65.

73 Mehta R, Paredes AZ, Pawlik TM. Redefining the "Honor Roll:" do hospital rankings predict surgical outcomes or receipt of quality surgical care? Am J Surg 2020;220:438-40.

74 Werner RM, Asch DA. The unintended consequences of publicly reporting quality information. JAMA 2005;293:1239-44.

75 Fung $\mathrm{CH}$, Lim Y-W, Mattke S, et al. Systematic review: the evidence that publishing patient care performance data improves quality of care. Ann Intern Med 2008;148:111-23.

76 Barnett ML, Keating NL, Christakis NA, et al. Reasons for choice of referral physician among primary care and specialist physicians. $J$ Gen Intern Med 2012;27:506-12.

77 Kinchen KS, Cooper LA, Levine D, et al. Referral of patients to specialists: factors affecting choice of specialist by primary care physicians. Ann Fam Med 2004;2:245-52.

78 Crow R, Gage H, Hampson S, et al. The measurement of satisfaction with healthcare: implications for practice from a systematic review of the literature. Health Technol Assess 2002;6:1-244.

79 Keller AC, Bergman MM, Heinzmann C, et al. The relationship between hospital patients' ratings of quality of care and communication. Int J Qual Health Care 2014;26:26-33.

80 de Groot IB, Otten W, Dijs-Elsinga J, et al. Choosing between hospitals: the influence of the experiences of other patients. Med Decis Making 2012;32:764-78.

81 Ferrua M, Sicotte C, Lalloué B, et al. Comparative quality indicators for hospital choice: do general practitioners care? PLoS One 2016;11:e0147296.

82 Mannion R, Goddard M. Public disclosure of comparative clinical performance data: lessons from the Scottish experience. J Eval Clin Pract 2003;9:277-86.

83 Birk HO, Henriksen LO. Which factors decided general practitioners' choice of hospital on behalf of their patients in an area with free choice of public hospital? A questionnaire study. BMC Health Serv Res 2012;12:126.

84 Ikkersheim D, Koolman X. The use of quality information by general practitioners: does it alter choices? A randomized clustered study. BMC Fam Pract 2013;14:95

85 Drevs F, Hinz V. Who chooses, who uses, who rates: the impact of agency on electronic word-of-mouth about hospitals stays. Health Care Manage Rev 2014;39:223-33.

86 Dobele A, Lindgreen A. Exploring the nature of value in the word-of-mouth referral equation for health care. J Market Manage 2011;27:269-90.

87 Damman OC, Hendriks M, Rademakers J, et al. How do healthcare consumers process and evaluate comparative healthcare information? A qualitative study using cognitive interviews. BMC Public Health 2009;9:423.

88 Zhang Y. Beyond quality and accessibility: source selection in consumer health information searching. J Assoc Inf Sci Technol 2014:65:911-27.

89 Gérard L, François M, de Chefdebien M, et al. The patient, the doctor, and the patient's loyalty: a qualitative study in French general practice. Br J Gen Pract 2016;66:e810-8.

90 Birkhäuer J, Gaab J, Kossowsky J, et al. Trust in the health care professional and health outcome: a meta-analysis. PLoS One 2017; 12:e0170988.
91 Bredart A, Bouleuc C, Dolbeault S. Doctor-patient communication and satisfaction with care in oncology. Curr Opin Oncol 2005; 17:351-4

92 Ong LML, de Haes JCJM, Hoos AM, et al. Doctor-patient communication: a review of the literature. Soc Sci Med 1995;40:903-18.

93 Anderson R, Barbara A, Feldman S. What patients want: a content analysis of key qualities that influence patient satisfaction. $J$ Med Pract Manage 2007;22:255-61.

94 Goetz K, Jossen M, Rosemann T, et al. Is patient loyalty associated with quality of care? results of a patient survey over primary care in Switzerland. Int J Qual Health Care 2019;31:199-204.

95 Smith D. Health care consumer's use and trust of health information sources. Journal of Healthc 2011;4:200-10.

96 Hildon Z, Allwood D, Black N. Patients' and clinicians' views of comparing the performance of providers of surgery: a qualitative study. Health Expect 2015;18:366-78.

97 Lucey CR, Sedmak D, Notestine M, et al. Rock stars in academic medicine. Acad Med 2010;85:1269-75.

98 Dunn LB, Iglewicz A, Zisook S. How to build a national Reputation for academic promotion. Roberts Academic Medicine Handbook: Springer, 2020: 515-23.

99 Coleman MM, Richard GV. Faculty career tracks at U.S. medical schools. Acad Med 2011;86:932-7.

100 Seibert SE, Kraimer ML, Liden RC. A social capital theory of career success. Academy Manage J 2001;44:219-37.

101 Salvatore D. Physician social capital: its sources, configuration, and usefulness. Health Care Manage Rev 2006;31:213-22.

102 Bleier JIS, Kann B. Academic goals in surgery. Clin Colon Rectal Surg 2013;26:212-7.

103 Chowdhury MM, Dagash H, Pierro A. A systematic review of the impact of volume of surgery and specialization on patient outcome. Br J Surg 2007:94:145-61.

104 Birkmeyer JD, Stukel TA, Siewers AE, et al. Surgeon volume and operative mortality in the United States. N Engl J Med Overseas Ed 2003;349:2117-27.

105 Maruthappu M, Gilbert BJ, El-Harasis MA, et al. The influence of volume and experience on individual surgical performance. Ann Surg 2015;261:642-7.

106 McElroy SE, Rice KG, Davis DE, et al. Intellectual humility: scale development and theoretical elaborations in the context of religious leadership. J Psychol Theol 2014;42:19-30.

107 Davis DE, Rice K, McElroy S, et al. Distinguishing intellectual humility and general humility. J Posit Psychol 2016;11:215-24.

108 Sasagawa M, Amieux PS. Concept map of dispositional humility among professionals in an interdisciplinary healthcare environment: qualitative synthesis]]\&gt. J Multidiscip Healthc 2019;12:543-54

109 Sasagawa M, Amieux PS. Dispositional humility of clinicians in an interprofessional primary care environment: a mixed methods study. J Multidiscip Healthc 2019;12:925-34.

110 Chancellor J, Lyubomirsky S. Humble beginnings: current trends, state perspectives, and hallmarks of humility. Soc Personal Psychol Compass 2013;7:819-33.

111 Long JC, Cunningham FC, Braithwaite J. Bridges, brokers and boundary spanners in collaborative networks: a systematic review. BMC Health Serv Res 2013;13:158-58.

112 Obstfeld D. Getting new things done: networks, brokerage, and the assembly of innovative action. Stanford University Press, 2017.

113 Shipilov AV, Li SX. Can you have your cake and eat it too? Structural holes' influence on status accumulation and market performance in collaborative networks. Adm Sci Q 2008;53:73-108.

114 Case CR, Maner JK. Divide and conquer: when and why leaders undermine the cohesive fabric of their group. $J$ Pers Soc Psychol 2014;107:1033-50.

115 Bidwell M, Fernandez-Mateo I. Relationship duration and returns to brokerage in the staffing sector. Organization Science 2010;21:1141-58

116 Obstfeld $\mathrm{D}$, networks $\mathrm{S}$. The tertius iungens orientation, and involvement in innovation. Admin Sci Quart 2005;50:100-30

117 Obstfeld D, Borgatti SP, Davis J. Brokerage as a process: decoupling third Party action from social network structure. Contemporary perspectives on organizational social networks. Emerald Group Publishing Limited, 2014.

118 Holmes DR, Rich JB, Zoghbi WA, et al. The heart team of cardiovascular care. J Am Coll Cardiol 2013;61:903-7.

119 Chu D, Anastacio MM, Mulukutla SR, et al. Safety and efficacy of implementing a multidisciplinary heart team approach for revascularization in patients with complex coronary artery disease: an observational cohort pilot study. JAMA Surg 2014;149:1109-12.

120 Reagans R, McEvily B. Network structure and knowledge transfer: the effects of cohesion and range. Adm Sci Q 2003;48:240-67. 
121 Burt RS. Structural holes and good ideas. Am J Sociol 2004;110:349-99.

122 Braithwaite J. Between-group behaviour in health care: gaps, edges, boundaries, disconnections, weak ties, spaces and holes. A systematic review. BMC Health Serv Res 2010;10:330.

123 Lewicki RJ, Tomlinson EC, Gillespie N. Models of interpersonal trust development: theoretical approaches, empirical evidence, and future directions. J Manage 2006;32:991-1022.

124 Ruhstaller T, Roe H, Thürlimann B, et al. The multidisciplinary meeting: an indispensable aid to communication between different Specialities. Eur J Cancer 2006;42:2459-62.

125 Mandl KD, Olson KL, Mines D, et al. Provider collaboration: cohesion, constellations, and shared patients. J Gen Intern Med 2014;29:1499-505.

126 Landon BE, Keating NL, Barnett ML, et al. Variation in patientsharing networks of physicians across the United States. JAMA 2012;308:265-73.

127 Manca DP, Breault L, Wishart P. A tale of two cultures: specialists and generalists sharing the load. Can Fam Physician 2011;57:576-84.

128 Greenberg JO, Barnett ML, Spinks MA. The "medical neighborhood": integrating primary and specialty care for ambulatory patients the medical neighborhood the medical neighborhood. JAMA Int Med 2014;174:454-7.

129 Uddin S. Exploring the impact of different multi-level measures of physician communities in patient-centric care networks on healthcare outcomes: a multi-level regression approach. Sci Rep 2016;6:20222.

130 McPherson M, Smith-Lovin L, Cook JM. Birds of a feather: Homophily in social networks. Annu Rev Sociol 2001;27:415-44.

131 Mclnnes E, Middleton S, Gardner G, et al. A qualitative study of stakeholder views of the conditions for and outcomes of successful clinical networks. BMC Health Serv Res 2012;12:1-12.

132 de Vaan M, Stark D, Vedres B. Game changer: the topology of creativity. AJS 2015;120:1144-94.

133 Kwon S-W, Rondi E, Levin DZ, et al. Network Brokerage: an integrative review and future research agenda. J Manage 2020;46:1092-120.

134 Kabo F. The architecture of network collective intelligence: correlations between social network structure, spatial layout and prestige outcomes in an office. Philosop Trans Royal Soc B: Biolog Sci 1753;2018:20170238.

135 Kabo F, Hwang Y, Levenstein M. Shared paths to the lab: a Sociospatial network analysis of collaboration. Environ Behav 2013;47:57-84.

136 Kabo FW, Cotton-Nessler N, Hwang Y, et al. Proximity effects on the dynamics and outcomes of scientific collaborations. Res Policy 2014;43:1469-85.

137 O'Brien MA, Grunfeld E, Sussman J, et al. Views of family physicians about survivorship care plans to provide breast cancer follow-up care: exploration of results from a randomized controlled trial. Curr Oncol 2015;22:252-9.

138 Dossett LA, Hudson JN, Morris AM, et al. The primary care provider (PCP)-cancer specialist relationship: A systematic review and mixed-methods meta-synthesis. CA Cancer J Clin 2017;67:156-69.

139 Vermeir P, Vandijck D, Degroote S, et al. Mutual perception of communication between general practitioners and hospital-based specialists. Acta Clin Belg 2015;70:350-6.

140 Rayman KM, Edwards J. Rural primary care providers' perceptions of their role in the breast cancer care continuum. J Rural Health 2010;26:189-95.
141 Coviello NE. Integrating qualitative and quantitative techniques in network analysis. Qualitative Mrkt Res: An Int J 2005;8:39-60.

142 Velden T, Lagoze C. The extraction of community structures from publication networks to support ethnographic observations of field differences in scientific communication. J Am Soc Inform Sci Technol 2013;64:2405-27.

143 Froehlich DE, Rehm M, Rienties BC. Mixed methods approaches to social network analysis, 2020.

144 Hollstein B. Qualitative approaches. In: The SAGE handbook of social network analysis, 2011: 404-16.

145 Macro BM. meso, micro: broadening the 'social' of social network analysis with a mixed methods approach. Quality \& Quantity 2016;50:2217-36.

146 A mixed method approach for identifying emerging fields and building collaborative teams: Leveraging network ethnography to design experimental interventions. ethnographic praxis in industry conference proceedings 2017.

147 Yousefi Nooraie R, Sale JEM, Marin A, et al. Social network analysis: an example of fusion between quantitative and qualitative methods. J Mix Methods Res 2020;14:110-24.

148 Moran-Ellis J, Alexander VD, Cronin A, et al. Triangulation and integration: processes, claims and implications. Qualitat Res 2006;6:45-59.

149 Froehlich DE, Van Waes S, Schäfer H. Linking quantitative and qualitative network approaches: a review of mixed methods social network analysis in education research. Rev Res Education 2020;44:244-68.

150 Wisdom J, Creswell JW. Mixed methods: integrating quantitative and qualitative data collection and analysis while studying patientcentered medical home models. Rockville: Agency for Healthcare Research and Quality, 2013.

151 Revisiting Bott to connect the dots: an exploration of the methodological origins of social network analysis. forum qualitative Sozialforschung/Forum: qualitative social research 2018.

152 Tashakkori A, Teddlie C. Sage handbook of mixed methods in social \& behavioral research. Sage, 2010.

153 Choudhry NK, Liao JM, Detsky AS. Selecting a specialist: adding evidence to the clinical practice of making ReferralsSelecting a SpecialistSelecting a specialist. JAMA 2014;312:1861-2.

154 Huang X, Rosenthal MB. Transforming specialty practice - the patient-centered medical neighborhood. $N$ Engl J Med Overseas Ed 2014;370:1376-9.

155 Geissler KH, Lubin B, Ericson KMM. The role of organizational affiliations in physician Patient-Sharing relationships. Med Care Res Rev 2020;77:165-75

156 Hoag JR, Resio BJ, Monsalve AF, et al. Differential safety between top-ranked cancer hospitals and their Affiliates for complex cancer surgery. JAMA Netw Open 2019;2:e191912.

157 Mendu ML, Kachalia A, Eappen S. Revisiting US news \& world report's hospital rankings-moving beyond mortality to metrics that improve care. J Gen Intern Med 2020

158 Gombeski WR, Claypool JO, Karpf M, et al. Hospital affiliations, cobranding, and consumer impact. Health Mark Q 2014;31:65-77.

159 Chiu AS, Resio B, Hoag JR, et al. US public perceptions about cancer care provided by smaller hospitals associated with large hospitals recognized for Specializing in cancer care. JAMA Oncol 2018;4:1008-9.

160 Saunders B, Sim J, Kingstone T, et al. Saturation in qualitative research: exploring its conceptualization and operationalization. Qual Quant 2018;52:1893-907. 